\title{
In Vivo and In Vitro Hepatoprotective Effects of Geranium koreanum Methanolic Extract via Downregulation of MAPK/Caspase-3 Pathway
}

\author{
Md Rashedunnabi Akanda, ${ }^{1,2}$ In-Shik Kim, ${ }^{1}$ Dongchoon Ahn, ${ }^{1}$ Hyun-Jin Tae, ${ }^{1}$ \\ Weishun Tian, ${ }^{1}$ Hyeon-Hwa Nam, ${ }^{3}$ Byung-Kil Choo, ${ }^{3}$ and Byung-Yong Park ${ }^{1}$ \\ ${ }^{1}$ College of Veterinary Medicine and Biosafety Research Institute, Chonbuk National University, Iksan 54596, Republic of Korea \\ ${ }^{2}$ Department of Pharmacology and Toxicology, Sylhet Agricultural University, Sylhet 3100, Bangladesh \\ ${ }^{3}$ Department of Crop Science \& Biotechnology, Chonbuk National University, Jeonju 54896, Republic of Korea
}

Correspondence should be addressed to Byung-Kil Choo; bkchoo@jbnu.ac.kr and Byung-Yong Park; parkb@jbnu.ac.kr

Received 2 February 2017; Accepted 5 June 2017; Published 5 July 2017

Academic Editor: Cheppail Ramachandran

Copyright (c) 2017 Md Rashedunnabi Akanda et al. This is an open access article distributed under the Creative Commons Attribution License, which permits unrestricted use, distribution, and reproduction in any medium, provided the original work is properly cited.

\begin{abstract}
Geranium koreanum (GK) is an indigenous Chinese herbal medicine widely used for the treatment of various inflammation and liver disorders. However, the exact mechanism of action of GK remains unknown. This study aimed to investigate the protective effect and related molecular mechanism of $\mathrm{GK}$ on $\mathrm{NaAsO}_{2}$-induced cytotoxicity in $\mathrm{HepG} 2$ cells and liver damage in mice. The cytoprotective role of GK was assessed on HepG2 cells using MTT assay. Oxidative stress and lactate dehydrogenase levels were measured with ROS and LDH assay. Histopathology and serum enzymes levels were estimated. The molecular mechanism was evaluated by qPCR and immunoblotting to ensure the hepatoprotective role of $\mathrm{GK}$ against $\mathrm{NaAsO}_{2}$ intoxication in mice. We found cotreatment with GK significantly attenuated $\mathrm{NaAsO}_{2}$-induced cell viability loss, intracellular ROS, and LDH release. Hepatic histopathology and serum biochemical parameters, ALT, and AST were notably improved by cotreatment with GK. Beside, GK markedly altered both mRNA and protein expression level of MAPK. The proapoptotic and antiapoptotic protein Bax/Bcl-2 ratio was significantly regulated by GK. Moreover, GK remarkably suppressed the postapoptotic transcription protein cleaved caspase-3 expression. The present study reveals that GK possesses hepatoprotective activity which is probably involved in the modulation of the MAPK/caspase-3 pathway.
\end{abstract}

\section{Introduction}

Arsenic is a naturally occurring metalloid toxicant that is known to contaminate groundwater due to its geographical structure. Environmental exposure to the inorganic arsenic compound is a global health concern for human and animal, especially in countries such as Bangladesh, India, and Pakistan $[1,2]$. Drinking water and industrial effluence are the leading sources of human exposure to inorganic arsenic [3]. The inorganic form of arsenic is more harmful than the organic state, and the most toxicologically effective arsenic compounds are in the trivalent oxidation state, mainly arsenic trioxide $\left(\mathrm{As}_{2} \mathrm{O}_{3}\right)$ and sodium arsenite $\left(\mathrm{NaAsO}_{2}\right)$ [4, 5]. Continued exposure to inorganic arsenic is associated with increased risk of liver, lung, skin, and kidney cancer. The liver is a major site of arsenic localization and biotransformation and, therefore, is affected by high arsenic level. Oxidative stress, genotoxicity, alterations in DNA methylation, cell proliferation, and induction of cell death have been reported followed by arsenic exposure $[6,7]$. This stress leads to damage of essential biomolecules and organs and may have a significant impact on the whole organism; the triggering of liver diseases serves as key pathophysiological evidence of this damage [8]. Oxidative stress is a widely standard hypothesis for $\mathrm{NaAsO}_{2}$-induced cytotoxicity [9]. Notably, generation of intracellular ROS level depends on the $\mathrm{NaAsO}_{2}$ exposure concentration and its biological effects on cells. Exposure to a lower concentration of $\mathrm{NaAsO}_{2}(0.5-5 \mu \mathrm{M})$ induces excess oxidative stress in cells [6], while exposure 
to relatively higher concentration of $\mathrm{NaAsO}_{2}(20-100 \mu \mathrm{M})$ causes apoptotic cell death [10].

ROS are highly reactive molecules which can damage a different cellular structure such as DNA, proteins, and lipids and alter their functions [11]. A proper balance between the generation of intracellular ROS and antioxidants is known to be vital for regulation of the biological consequences. Arsenic-mediated oxidative stress leads to adverse biological processes, including cell death following stimulation of MAPK and apoptotic signals [12, 13]. Sulfhydryl-reactive compound $\mathrm{NaAsO}_{2}$ activates MAPK pathway and concurrently nuclear translocation of transcription factors which modify gene expression through phosphorylation-dependent substrate stimulation $[13,14]$. MAPK cascade consists of three major kinases: ERK, JNK, and p38. Particularly, the activation of JNK and p38 activates apoptosis in response to oxidative stress and DNA damage [15]. Also, ERK activity promotes apoptosis by induction of mitochondrial cytochrome $c$ release [16]. Beside, Bcl-2 family members provide the most important controlling mechanism for apoptosis and a major site of their action is the mitochondria. The relationship between the proapoptotic protein, Bax, and the antiapoptotic protein, $\mathrm{Bcl}-2$, regulates mitochondria-dependent apoptotic cell death by activating the downstream transcription protein caspase-3 [17]. Caspase activation is under the direct control of kinases and the indirect control of phosphorylation via regulation of apoptotic protein [18]. Hence, DNA fragmentation and protein phosphorylation lead to triggering of caspase and serine/threonine protein phosphorylation activation [19]. Thus, the inhibition of apoptotic signaling pathway activated by $\mathrm{NaAsO}_{2}$-induced oxidative damage may be an excellent strategy for treatment of hepatic disorders.

Phytomedicine and active ingredients from plants have received considerable attention; these antioxidant agents may offer some protection against oxidative stress and play a potential role in reducing the toxicity of trivalent arsenite [20]. Traditional herbal medicine is a potential source for effective and alternative remedies for liver diseases [21]. Antioxidants are able to donate electrons and neutralize free radicals resulting in the prevention of cell injuries [22]; however, there is limited information on the molecular mechanism and biological activities of these compounds. Recently, the search for effective and natural phytocompounds with antioxidant activity has been strengthened [23]. We describe here for the first time a simple and reliable process for obtaining an extract of GK with which to synthesize a solution with a strong effectiveness against $\mathrm{NaAsO}_{2}$-induced liver toxicity both in vivo and in vitro. Traditionally GK extract has been used as Chinese traditional medicine to treat many diseases such as itching, bruising, enteritis, chronic diarrhea, and liver disorder and GK contains widely tannins, quercetin, gallic acid, and succinic acid [24]. An earlier study reported that GK extract shows antibacterial activities [24]. Since antioxidant properties are important factors in the management of liver disease, thus GK is suggested to be an effective hepatoprotective medicine. Therefore, based on the traditional uses and pharmacological activities of GK, our study investigates the hepatoprotective role of GK on $\mathrm{NaAsO}_{2}$-induced oxidative damage in vitro and in vivo.

\section{Materials and Methods}

2.1. Chemicals and Antibodies. Sodium arsenite $\left(\mathrm{NaAsO}_{2}\right), 3-$ (4,5-dimethylthiazol-2-yl)-2,5-diphenyltetrazolium bromide (MTT), gallic acid, rutin, penicillin/streptomycin, hematoxylin, eosin, and protease inhibitor were purchased from Sigma-Aldrich (St. Louis, MO, USA). Fetal bovine serum (FBS), Dulbecco's modified Eagle's medium (DMEM), and other cell culture reagents were obtained from Gibco (Carlsbad, CA, USA). Dimethyl sulfoxide (DMSO) was from Bioshop (Canada). RNA extraction kits were purchased from RiboEx and Hybrid-R (Gene All, South Korea). Tissue protein extraction (T-PER), cDNA synthesis (ReverTra Ace qPCR RT Kit), and BCA protein assay kits were purchased from Thermo Scientific (Waltham, Massachusetts, USA). SYBR green qPCR kit was purchased from TOYOBO (Japan). Primary antibodies (phospho-ERK1/2, phospho-JNK phospho p38, Bax, Bcl-2, cleaved caspase-3, and caspase-3) and $\beta$-actin were purchased from Cell Signaling, Danvers, MA, USA. Secondary antibody (goat anti-rabbit IgG-HRP) was purchased from Santa Cruz (Santa Cruz, CA, USA). ECL detection kit was acquired from Abfrontire (South Korea), and the ALT and AST kits were from ASAN (South Korea). Lactate dehydrogenase (LDH) cytotoxicity assay kit was obtained from TAKARA (Japan), and the ROS detection kit was from Promega (USA). Zoletil 50 was supplied by Virbac S.A. (France).

2.2. Plant Materials and Extraction. The whole plant of GK was collected from the Crop Science and Biotechnology Laboratory, College of Agriculture and Life Science, Chonbuk National University, South Korea. The dried plant was boiled 3 times in $100 \%$ methanol for $2 \mathrm{~h}$. The extract was filtered, concentrated under vacuum, and dried with a lyophilizer. The powdered extract was dissolved in DMSO and sterilized by filtering through a $0.22 \mu \mathrm{m}$ syringe filter. The maximum concentration of DMSO used for in vitro studies was $0.1 \%$. For in vivo study, GK extract was dissolved in distilled water. The dried extract was kept in $-20^{\circ} \mathrm{C}$.

2.3. Determination of Total Phenolic and Flavonoid Content. Total phenolic and flavonoid content of GK extract was measured according to the previously described method [25].

2.4. Cell Culture. HepG2 cells were maintained at $37^{\circ} \mathrm{C}$ in a $5 \% \mathrm{CO}_{2}$ humidified incubator. Cells were cultured in DMEM enriched with $10 \%$ FBS and $1 \%$ penicillin and streptomycin. The culture media were changed every 2 days and subcultured when cells reached about $90 \%$ confluency.

2.5. Evaluation of Cell Viability. The MTT assay provides a sensitive determination of the metabolic status of cellular mitochondrial enzymes. We did MTT assay according to a previously described method with slight modification [26]. HepG2 cells $\left(1 \times 10^{4}\right.$ cells/well in 96 well plates $)$ were cultured at $37^{\circ} \mathrm{C}$ for $24 \mathrm{~h}$ with $10 \% \mathrm{FBS}$ prior to experimental 
treatment. For evaluating the cytotoxicity of GK extract, cells were treated with $\operatorname{GK}(1,5,10,20$, and $40 \mu \mathrm{g} / \mathrm{mL})$ for $24 \mathrm{~h}$. In contrast, measuring the cell viability, cells were pretreated for $1 \mathrm{~h}$ with different concentration of GK (5, 10 , and $20 \mu \mathrm{g} / \mathrm{mL}$ ) in FBS-free media and then cotreated with $\mathrm{GK}$ and $\mathrm{NaAsO}_{2}(10 \mu \mathrm{M})$ for an additional $24 \mathrm{~h}$. The culture medium was replaced by $0.5 \mathrm{mg} / \mathrm{mL}$ MTT solution and cultured for another $2 \mathrm{~h}$. MTT solution was carefully aspirated and blue formazan solubilized in DMSO. OD was measured at a wavelength of $570 \mathrm{~nm}$ using a tunable versa max microplate reader (Molecular Device, USA).

2.6. Measurement of Intracellular ROS and LDH. Intracellular ROS generation and $\mathrm{LDH}$ release into the culture medium by dead cells were determined using the ROS detection kit and LDH cytotoxicity assay kit, according to manufacturer instructions. HepG2 cells $\left(1 \times 10^{4}\right.$ cells/well in 96 well plates $)$ were cultured at $37^{\circ} \mathrm{C}$ for $24 \mathrm{~h}$. After adherence, cells were pretreated with $\operatorname{GK}(5,10$, and $20 \mu \mathrm{g} / \mathrm{mL})$ for $1 \mathrm{~h}$ and followed by cotreatment with $10 \mu \mathrm{M} \mathrm{NaAsO}$ and GK for another $24 \mathrm{~h}$. Absorbance was measured at $490 \mathrm{~nm}$ using a tunable versa max microplate reader.

2.7. Animal Management and Experimental Design. 6-weekold ICR mice were maintained in accordance with the animal welfare regulation of the Institutional Animal Care and Use Committees, Chonbuk National University Laboratory Animal Centre, South Korea. Mice were kept in standard mouse cages with an ad libitum supply of food and distilled water. Temperature $\left(23 \pm 2^{\circ} \mathrm{C}\right)$, humidity (35-60\%), and photoperiod cycle ( $12 \mathrm{~h}$ light and $12 \mathrm{~h}$ dark) were maintained over the experimental period. Mice were adapted to the laboratory atmosphere for 1 week before starting the experiment. We followed previously established method for in vivo study [27]. Briefly, a total 48 mice were randomly divided into four groups: (1) normal control mice were treated with normal saline, (2) toxic control mice were treated with $\mathrm{NaAsO}_{2}$ once daily $(10 \mathrm{mg} / \mathrm{kg}$ body weight, p.o., for 10 days), (3) experimental mice were treated with GK extract once daily ( $20 \mathrm{mg} / \mathrm{kg}$ body weight, p.o., for 15 days) prior to treatment with $\mathrm{NaAsO}_{2}(10 \mathrm{mg} / \mathrm{kg}$ body weight, p.o., for 10 days), and (4) experimental mice were treated with GK extract once daily (20 mg/kg body weight, p.o., for 15 days). After the experimental period, mice were fasted overnight and sacrificed under anesthetized using Zoletil 50. Blood samples were collected for serum biochemical analyses. Liver samples were collected and immediately fixed with $10 \% \mathrm{NBF}$ for histopathological analysis and kept in $-80^{\circ} \mathrm{C}$ for qPCR and immunoblotting analyses.

2.8. Histopathological Analysis of Liver. Liver samples were excised for histopathological evaluation. Pieces of the same lobe of liver from each mouse were immediately fixed in 10\% NBF. Samples were processed in an autoprocessor (Excelsior ES, Thermo Scientific, USA). After embedding in paraffin, $5 \mu \mathrm{m}$ sections of liver tissue were stained with hematoxylin and eosin and mounted on a glass slide. Staining by hematoxylin and eosin was utilized to explore histological architecture and apoptotic changes among hepatocytes. Digital images were obtained using a Leica DM2500 microscope (Leica Microsystems, Germany) at a fixed 200x magnification. The diameter of the portal vein was measured using image measurement software (iSolution DTM).

2.9. Serum Biochemical Assessment. For assessment of liver function, sera were collected from experimental mice. We followed previously recognized technique for serum separation [28]. At first, blood samples were collected directly from the heart and incubated for $30 \mathrm{~min}$ at room temperature. Whole blood was centrifuged at $3000 \mathrm{rpm}$ for $15 \mathrm{~min}$ at $4^{\circ} \mathrm{C}$ to collect the sera, after which serum biochemical components including ALT and AST were analyzed according to the manufacturer reference.

2.10. $q P C R$ Analysis. Total RNA was extracted from liver tissue according to the manufacturer's instructions, and RNA concentration was quantified using a BioSpec-nanospectrophotometer (Shimadzu Biotech, Tokyo, Japan) at a $260 / 280 \mathrm{~nm}$ ratio. All RNA samples were stored at $-80^{\circ} \mathrm{C}$ until use. For cDNA synthesis, total RNA $(3 \mu \mathrm{g})$ was used, and the cDNA synthesis procedure was performed according to the manufacturer's instructions. qPCR was performed using the SYBR Green Real-Time PCR master mix with the Roche LightCycler ${ }^{\mathrm{TM}}$, and the following conditions were maintained to complete 40 cycles: predenaturation $95^{\circ} \mathrm{C}$ for $30 \mathrm{sec}$, denaturation $95^{\circ} \mathrm{C}$ for $5 \mathrm{sec}$, annealing $55^{\circ} \mathrm{C}$ for $10 \mathrm{sec}$, and extension for $72^{\circ} \mathrm{C}$ for $15 \mathrm{sec}$. The qPCR reaction system was performed according to manufacturer's instructions. The relative mRNA expression was analyzed by normalized the target mRNA value and $\beta$-actin. The nucleotide sequences of the primers are presented in Table 1 [29].

2.11. Immunoblotting Analysis. For immunoblotting analysis, liver tissue lysates were prepared in lysis buffer: containing T-PER, PMSF, Na3VO4, and protease inhibitor cocktail. The total protein concentration of lysed liver was measured using the BCA protein assay kit. An equal amount of protein was separated by $12 \%$ SDS-PAGE and transferred to a nitrocellulose membrane. The membrane was blocked with 5\% BSA or $5 \%$ nonfat skim milk in TBST or PBST for $2 \mathrm{~h}$ at room temperature followed by incubation with primary antibodies against pERK, pJNK, pp38, Bax, Bcl-2, caspase-3, cleaved caspase- 3 , and $\beta$-actin overnight at $4^{\circ} \mathrm{C}$. The blot was washed and then incubated with secondary antibody for $2 \mathrm{~h}$. Proteins were detected using an ECL detection kit, and images were obtained using a UV imaging system (LAS-400 image system, GE Healthcare, UK). $\beta$-Actin was used as the control.

2.12. Statistical Analysis. Data were analyzed with Graph Pad Prism 5.0 and expressed as mean \pm SEM. Group comparisons were performed using one-way and two-way analysis of variance (ANOVA) followed by Bonferroni post hoc tests. The minimum statistical significance was considered at $p<$ 0.05 for all analyses.

\section{Results}

3.1. Analysis of Total Phenolic and Flavonoid Content of GK. Phenolic and flavonoid contents are the secondary 
TABLE 1: Nucleotide sequence of the primers for qPCR.

\begin{tabular}{|c|c|c|c|}
\hline Gene & Primers sequence $\left(5^{\prime}-3^{\prime}\right)$ & Size (bp) & GenBank accession number \\
\hline \multirow{2}{*}{ ERK } & TCAGAGGCAGGTGGATCTCT & \multirow{2}{*}{109} & \multirow{2}{*}{ NM_011949.3 } \\
\hline & ACGGGGAGGACTCTGTTTTT & & \\
\hline \multirow{2}{*}{ JNK } & CGGAACACCTTGTCCTGAAT & \multirow{2}{*}{93} & \multirow{2}{*}{ NM_016700.4 } \\
\hline & CACATCGGGGAACAGTTTCT & & \\
\hline \multirow{2}{*}{ p38 } & AGCCAATTCCAGTGTTGGAC & \multirow{2}{*}{120} & \multirow{2}{*}{ NM_011951.3 } \\
\hline & TTCTGGGCTCCAAATGATTC & & \\
\hline \multirow{2}{*}{$\beta$-Actin } & AGAAGATCTGGCACCACACC & \multirow{2}{*}{195} & \multirow{2}{*}{ NM_007393.5 } \\
\hline & TACGACCAGAGGCATACAGG & & \\
\hline
\end{tabular}

TABLE 2: Total phenolic, flavonoid, and extraction yield of GK.

\begin{tabular}{lccc}
\hline Plant extract & $\begin{array}{c}\text { Total phenolics } \\
(\mathrm{mg} \mathrm{GAE} / \mathrm{g} \text { extract })\end{array}$ & $\begin{array}{c}\text { Total flavonoids } \\
(\mathrm{mg} \text { RU/g extract })\end{array}$ & Total yield (\%) \\
\hline Methanolic extract & $86.858 \pm 0.132$ & $182.964 \pm 5.428$ & 26.9 \\
\hline
\end{tabular}

metabolites of plant which exhibits a series of biological activities and certainly, possessing antioxidant properties. The total phenolic and flavonoid contents of GK extract were investigated and presented in Table 2.

3.2. GK Reduced $\mathrm{NaAsO}_{2}$-Induced Cytotoxicity in HepG2 Cells. We performed MTT assay to evaluate the mechanism responsible for the hepatoprotective effects of GK against $\mathrm{NaAsO}_{2}$-induced damage in HepG2 cells. To investigate the cytotoxicity of GK extract, the MTT assay was done using a different concentration of GK extract $(1,5,10,20$, and $40 \mu \mathrm{g} / \mathrm{mL}$ ) for $24 \mathrm{~h}$. Our data showed that cell viability was not significantly altered by incubation with the GK extract ( 1 , 5,10 , and $20 \mu \mathrm{g} / \mathrm{mL}$ ) for $24 \mathrm{~h}$ while GK $40 \mu \mathrm{g} / \mathrm{mL}$ significantly decreased the cell viability (Figure 1(a)). For cell viability, at the end of the $24 \mathrm{~h}$ treatment period, incubation with $10 \mu \mathrm{M} \mathrm{NaAsO}$ alone reduced cell viability (\%) to $53.55 \pm$ 2.797 compared to control. This cytotoxic effect was attenuated by cotreatment with GK in a dose-dependent manner; cotreatment with GK $(5,10$, and $20 \mu \mathrm{g} / \mathrm{mL})$ enhanced cell viability (\%) $60.65 \pm 2.873,70.52 \pm 1.439$, and $80.45 \pm$ 2.088, respectively (Figure 1(b)). Similarly, observations of cells morphology with light microscopy demonstrated that a number of cells became pyknotic and apoptotic with $\mathrm{NaAsO}_{2}$ alone compared to GK cotreated groups. The pyknotic and apoptotic cell populations were reduced in the GK extract cotreated groups in a dose-dependent manner (Figure 1(c)). Together, these results indicate that GK had hepatoprotective effects against $\mathrm{NaAsO}_{2}$-induced cytotoxicity in HepG2 cells.

3.3. GK Inhibited ROS and LDH Release in HepG2 Cells. Experimental evidence indicates that exposure to arsenic induces oxidative stress [30]. The hepatoprotective effect of GK was confirmed with ROS and LDH assays. After treatment with $10 \mu \mathrm{M} \mathrm{NaAsO}_{2}$ for $24 \mathrm{~h}$, there was a significant increase in intracellular ROS generation (\%) to $169.65 \pm 4.268$ of control and $\mathrm{LDH}$ release (\%) up to $172.77 \pm 2.846$ of control. However, cotreatment with GK notably reduced intracellular ROS and LDH level. At GK concentrations of 5, 10, and
$20 \mu \mathrm{g} / \mathrm{mL}$, intracellular ROS (\%) decreased to $155.06 \pm 3.193$, $131.36 \pm 3.364$, and 110.44 \pm 4.908 , respectively (Figure 2(a)), and $\mathrm{LDH}$ release (\%) significantly declined to $154.89 \pm 3.345$, $135.63 \pm 3.367$, and $121.03 \pm 2.002$, respectively (Figure $2(b)$ ). Together, these data indicate that GK protected HepG 2 cells from the damaging oxidative effects caused by $\mathrm{NaAsO}_{2}$.

3.4. GK Improved the Histopathology of Liver and Body Weight. Microscopic analysis of the liver revealed normal hepatocyte structures arrange around the portal vein in both control and GK cotreated group. Examination of mice liver from the $\mathrm{NaAsO}_{2}$ treated group $(10 \mathrm{mg} / \mathrm{kg})$ showed slight hydropic and degenerative nuclei, cellular infiltration, and dilation of the portal vein. Histopathological changes induced by $\mathrm{NaAsO}_{2}$ were remarkably improved by cotreatment with GK $(20 \mathrm{mg} / \mathrm{kg})$, and in addition, GK $(20 \mathrm{mg} / \mathrm{kg})$ alone did not show damaging effects in liver tissue (Figure 3 ). The portal vein diameter significantly reduced by the GK cotreatment (Figure 4(a)). Besides, the body weight of mice was significantly increased at day 7 and day 14 in the GK cotreated group compared to the $\mathrm{NaAsO}_{2}$ alone (Figure 4(b)).

3.5. GK Treatment Restored Serum Liver Enzymes Activity. Serum biochemical parameters serve as an important indicator of physiological abnormalities in liver intoxication. We found that the levels of the serum cytosolic enzymes ALT $(101.58 \pm 9.473 \mathrm{IU} / \mathrm{L})$ and AST $(155.75 \pm 11.461 \mathrm{IU} / \mathrm{L})$ were considerably higher in $\mathrm{NaAsO}_{2}$-intoxicated mice than in normal controls (ALT, $43.39 \pm 4.916 \mathrm{IU} / \mathrm{L}$, and AST, 88.83 $\pm 4.375 \mathrm{IU} / \mathrm{L})$. Cotreatment with GK significantly improved liver function by reducing ALT and AST level (60.29 \pm 10.160 IU/L and $108.40 \pm 5.061 \mathrm{IU} / \mathrm{L}$, resp.) as compared to $\mathrm{NaAsO}_{2}$ alone (Figure 5). These data indicate that GK protected against the hepatic damaging effects caused by $\mathrm{NaAsO}_{2}$ intoxication in mice.

3.6. GK Attenuated the Upregulation of $m R N A$ Expression of MAPK (ERK, JNK, and p38). To determine whether MAPK signaling pathways were involved in $\mathrm{NaAsO}_{2}$-induced 


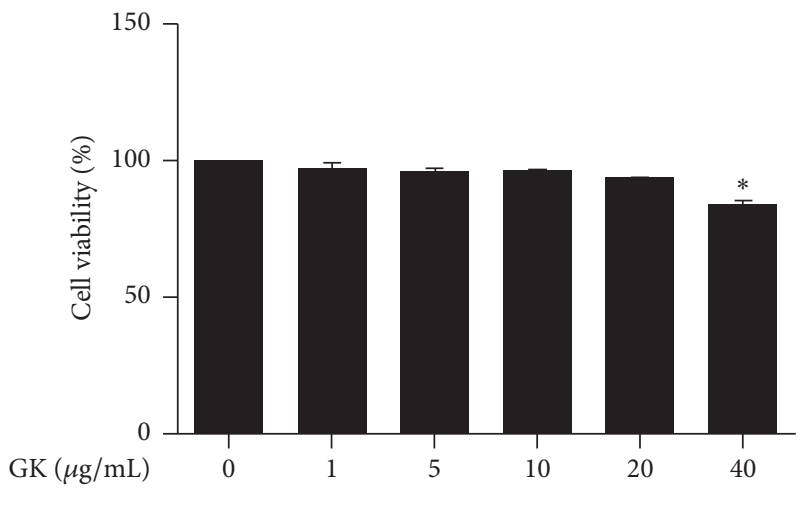

(a)
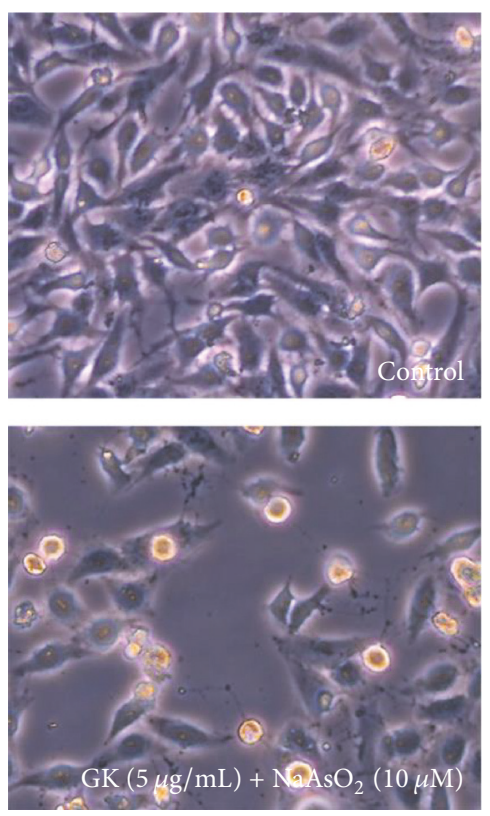
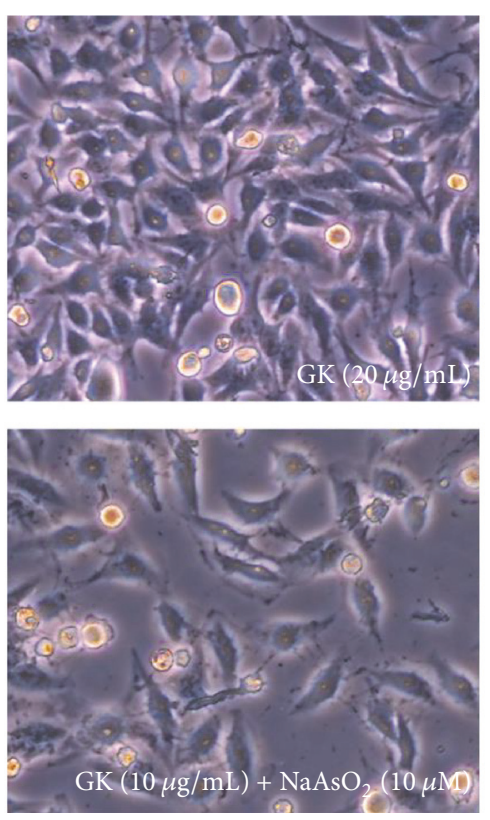

(c)

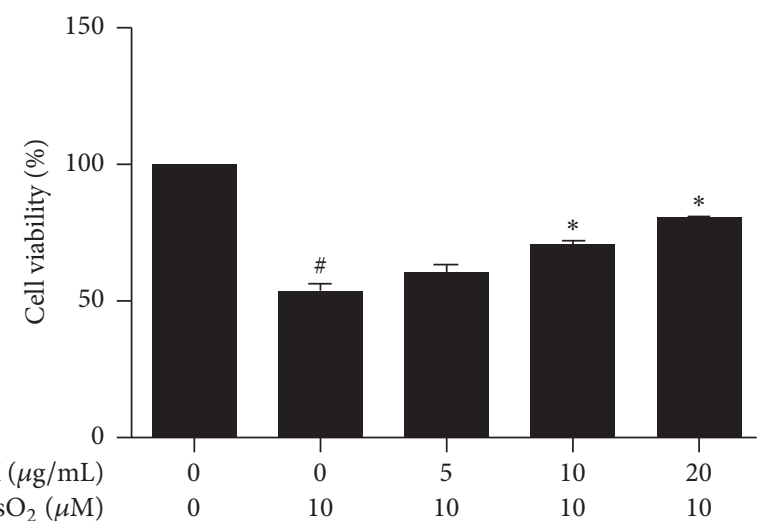

(b)
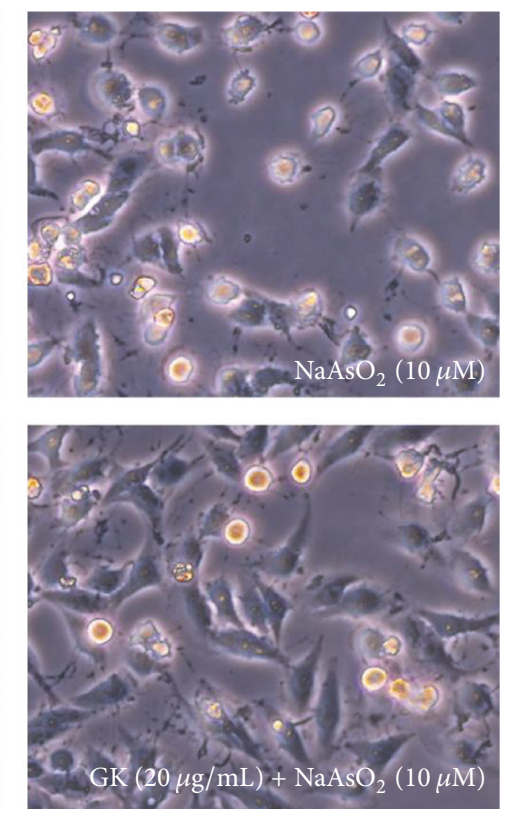

FIgUrE 1: Hepatoprotective effects of GK against $\mathrm{NaAsO}_{2}$-induced toxicity in HepG2 cells. (a) Cytotoxicity and (b) cell viability were determined by MTT assay and (c) observation of HepG2 cell morphology. Cells were pretreated with different concentration of GK for $1 \mathrm{~h}$, followed by cotreatment with $10 \mu \mathrm{M} \mathrm{NaAsO}$, for 24 h. ${ }^{*} p<0.05$ when compared with the control and ${ }^{*} p<0.05$ when compared with $\mathrm{NaAsO}_{2}$ treated. Data are expressed as mean \pm SEM from triplicate experiments.

hepatotoxicity, we tested $\mathrm{NaAsO}_{2}$ stimulated expression and modulation of ERK, JNK, and p38 genes in liver tissue with and without GK cotreatment. We found treatment with $\mathrm{NaAsO}_{2}(10 \mathrm{mg} / \mathrm{kg})$ markedly increased gene expression level of ERK, JNK, and p38 (155.34\%, 139.16\%, and 119.24\%) compared to control (100\%), and this elevated expression level was significantly attenuated $(112.64 \%, 108.89 \%$, and $104.94 \%$, resp.) by cotreatment with GK $(20 \mathrm{mg} / \mathrm{kg})$ as compared with $\mathrm{NaAsO}_{2}$ alone. Thus, GK significantly inhibited mRNA expression of MAPK, which led to hepatoprotection in $\mathrm{NaAsO}_{2}$ intoxication in mice (Figure 6).

3.7. GK Suppressed MAPK (ERK1/2, JNK, and p38) and Caspase-3 Signaling Pathways and Maintained the Bax/Bcl2 Expression Ratio. To understand the possible molecular pathways of hepatoprotection by GK extract, we evaluated
MAPK family protein which played a crucial role in arsenicinduced hepatic damage and apoptosis. We analyzed the phosphorylation status of ERK1/2, JNK, and p38 and examined the effects of GK on the proapoptotic protein (Bax), the antiapoptotic protein ( $\mathrm{Bcl}-2)$, and the triggering of a cleaved caspase- 3 apoptotic factor by immunoblotting. We found treatment with $\mathrm{NaAsO}_{2}(10 \mathrm{mg} / \mathrm{kg})$ significantly upregulated phosphorylation of the MAPK family protein expression compared to control. Phosphorylated (ERK1/2, JNK, and p38) protein level was remarkably attenuated by GK $(20 \mathrm{mg} / \mathrm{kg})$ cotreatment compared to $\mathrm{NaAsO}_{2}$ alone (Figure 7). Also, in comparison with the control, the expression level of Bax and $\mathrm{Bcl}-2$ was increased and decreased markedly in the $\mathrm{NaAsO}_{2}$-treated group while being contrasted to the $\mathrm{NaAsO}_{2}$-treated group; the $\mathrm{Bax} / \mathrm{Bcl}-2$ expression was significantly decreased and increased respectively 


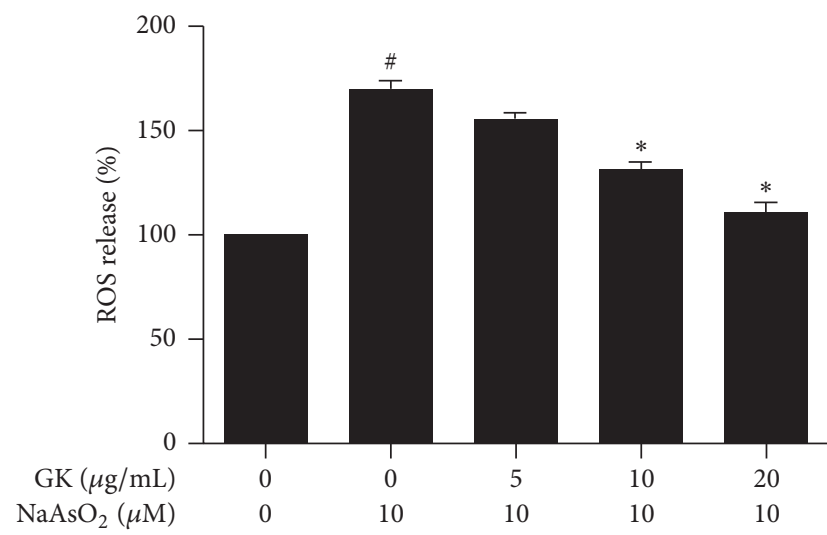

(a)

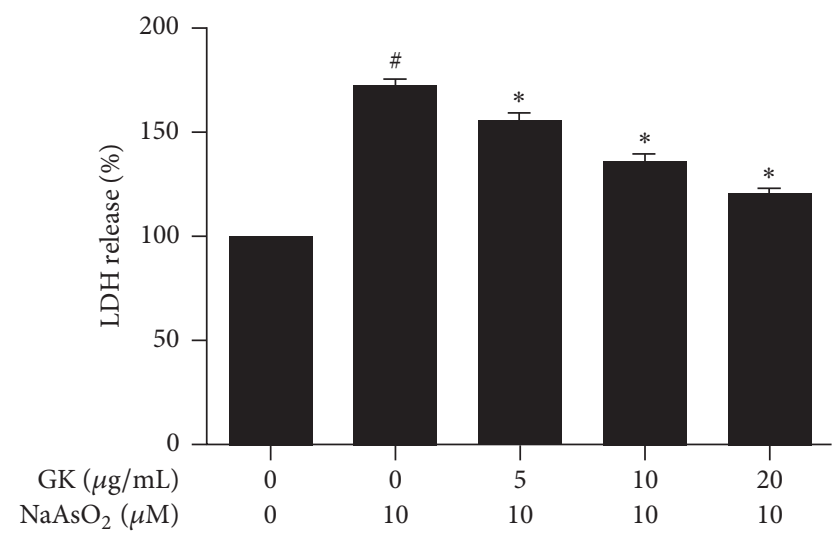

(b)

FIGURE 2: GK extract suppressed the release of intracellular ROS and LDH in HepG2 cells. (a) ROS and (b) LDH levels were measured. Cells were pretreated with different concentration of GK for $1 \mathrm{~h}$, followed by cotreatment with $10 \mu \mathrm{M} \mathrm{NaAsO}_{2}$ for $24 \mathrm{~h} .{ }^{\#} p<0.05$ when compared with the control and ${ }^{*} p<0.05$ when compared with $\mathrm{NaAsO}_{2}$ treated. Data are expressed as mean \pm SEM from triplicate experiments.

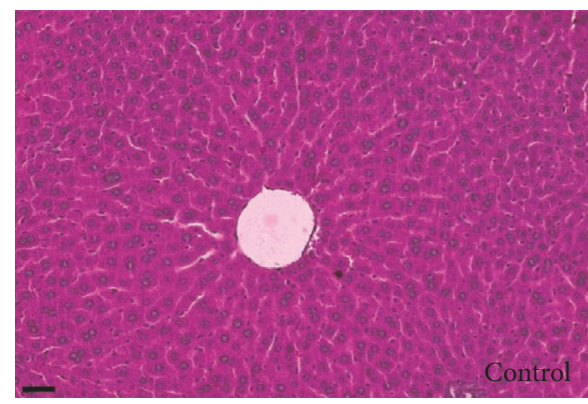

(a)

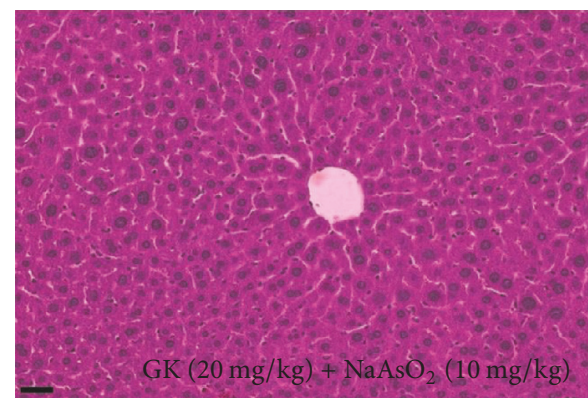

(c)

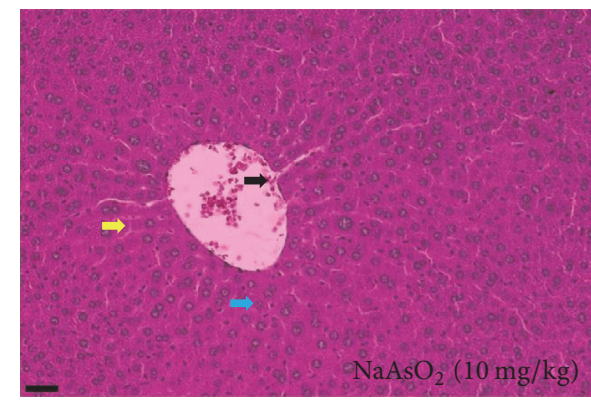

(b)

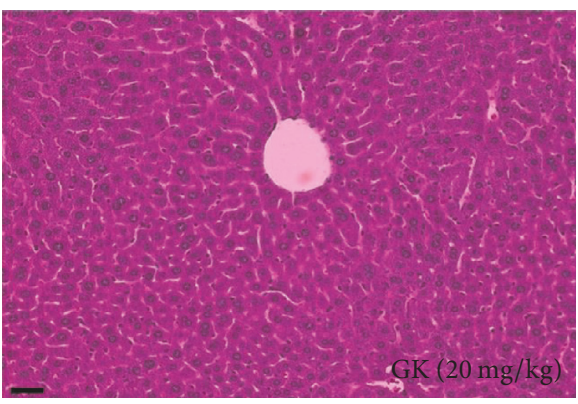

(d)

FIGURE 3: GK improved liver histology in experimental mice. Untreated mice were kept as a control to compare histological changes induced by $\mathrm{NaAsO}_{2}$. (b) $\mathrm{NaAsO}_{2}(10 \mathrm{mg} / \mathrm{kg})$ treated mice liver. The black arrow indicates the dilated portal vein, the pale green arrow indicates the degenerative nucleus, and the yellow arrow indicates blurred cytoplasm. In contrast, cotreatment with GK (20 mg/kg) improved histological changes as compared to $\mathrm{NaAsO}_{2}$ alone. Scale bar $200 \mu \mathrm{M}$.

in the GK cotreatment group. Thus, the relative expression level of Bax/Bcl-2 family proteins was also significantly regulated by GK cotreatment (Figure 8). Since the apoptotic factor caspase-3 plays a vital role in hepatoprotection, we investigated cleaved caspase- 3 protein level following treatment with $\mathrm{NaAsO}_{2}$. Expression of cleaved caspase3 was markedly increased by treatment with $\mathrm{NaAsO}_{2}$. In contrast, cotreatment with $\mathrm{GK}(20 \mathrm{mg} / \mathrm{kg})$ notably reduced the expression level of cleaved caspase- 3 related to $\mathrm{NaAsO}_{2}$ alone (Figure 8). These results support that GK significantly inhibited phosphorylation of MAPK, well-regulated the $\mathrm{Bax} / \mathrm{Bcl}-2$ expression ratio, and concurrently suppressed the activation of apoptotic factor cleaved caspase- 3 expression that led to the hepatoprotection.

\section{Discussion}

Sodium arsenite is a ubiquitous metalloid has been recognized as significant risk factor for public health concern. Globally, about 200 million people are exposed to inorganic 


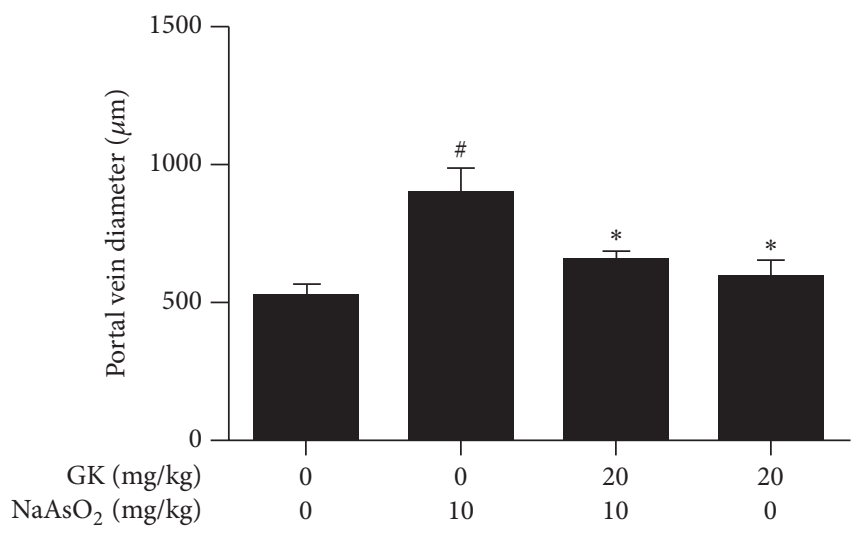

(a)

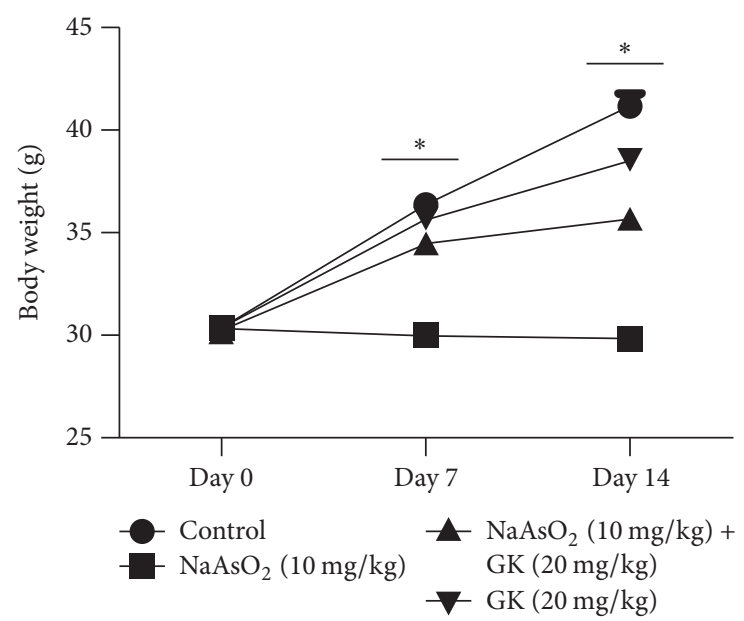

(b)

FIGURE 4: GK reduced the portal vein diameter and increased the body weight in experimental mice. (a) The diameter of the portal vein was increased in $\mathrm{NaAsO}_{2}(10 \mathrm{mg} / \mathrm{kg})$ treated liver. Cotreatment with GK $(20 \mathrm{mg} / \mathrm{kg})$ significantly decreased the portal vein diameter and (b) the average body weight of the GK cotreated group was significantly increased as compared to the $\mathrm{NaAsO}_{2}$ alone in day 7 and day $14 .{ }^{\#} p<0.05$ when compared with the control and ${ }^{*} p<0.05$ when compared with $\mathrm{NaAsO}_{2}$ treated. Data are expressed as mean \pm SEM.
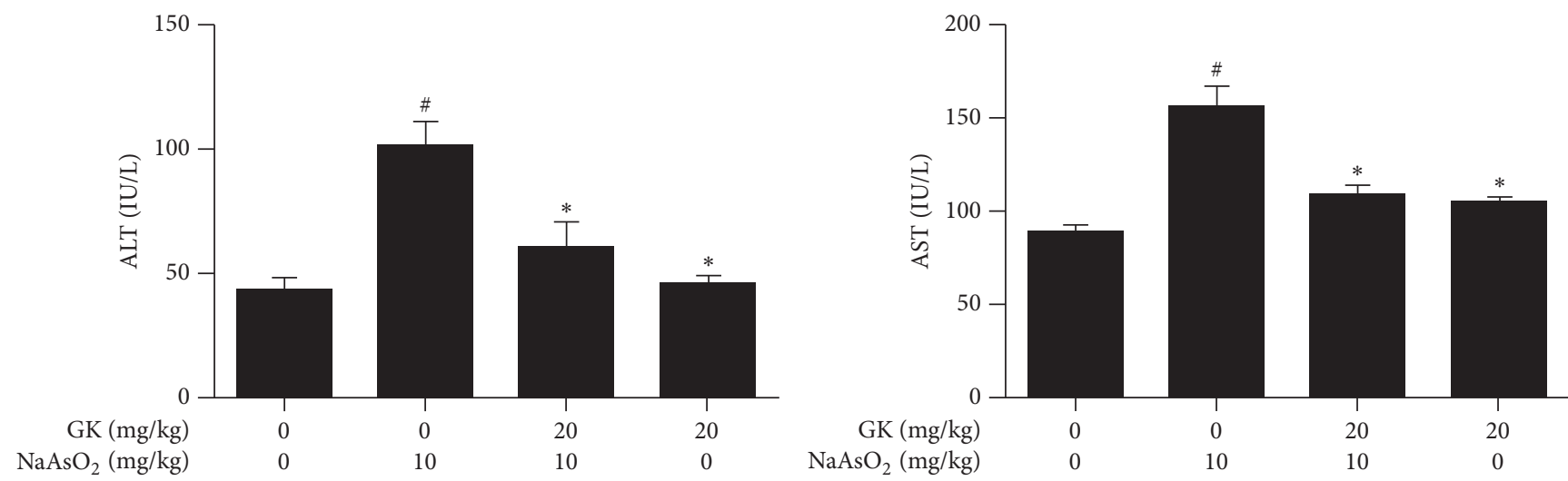

FIgURE 5: Effects of GK on serum biochemical parameters in experimental mice. Both ALT and AST were increased in $\mathrm{NaAsO}_{2}(10 \mathrm{mg} / \mathrm{kg})$ intoxicated mice. Cotreatment with GK $(20 \mathrm{mg} / \mathrm{kg})$ significantly decreased the serum ALT and AST level. ${ }^{*} p<0.05$ when compared with the control and ${ }^{*} p<0.05$ when compared with $\mathrm{NaAsO}_{2}$ treated. Data are expressed as mean \pm SEM.

arsenic compounds through underground contaminated drinking water [31]. Extensive studies have been undertaken to increase understanding of the mechanisms of arsenic intoxication with the goal of designing treatment and assigning proper levels of hazard to exposure. Much progress has been made in the development of equipment capable of removing detectable levels of arsenic and other heavy metals from drinking water. However, it is equally imperative to understand the molecular mechanisms of arsenic toxicity. The key to understanding the pathogenesis of these diseases lies in the myriad of cellular processes that are changed or damaged by arsenic compounds. Treatment preventing the hepatic damage may lead to prospective therapeutic strategies against the hepatotoxicity and GK extract may provide a novel therapeutic candidate. In this study, we revealed that GK can be used as a novel indigenous phytomedicine due to its strong hepatoprotective effects against $\mathrm{NaAsO}_{2}$-mediated oxidative stress in vitro and in vivo.

Phenolic and flavonoid are the most important plant secondary metabolites and possessing strong antioxidant capacity $[32,33]$. The antioxidant ability of them was mainly due to their redox properties, which allow them to act as reducing agents, oxygen scavengers, and transition metal ions chelator [34]. In our study, we found a considerable amount of phenolic and flavonoid content of GK extract that may be the major contributor for the antioxidant role against oxidative stress-induced hepatic damage. $\mathrm{NaAsO}_{2}$-induced cytotoxicity is the common method for the measurement of the potential hepatoprotective role of antioxidants [35, 36]. We found cotreatment with the GK increased cell viability and improved the cell morphology. Cellular proliferation, DNA repair, methylation, interactions with thiol and phosphate groups, and generation of ROS and signaling 

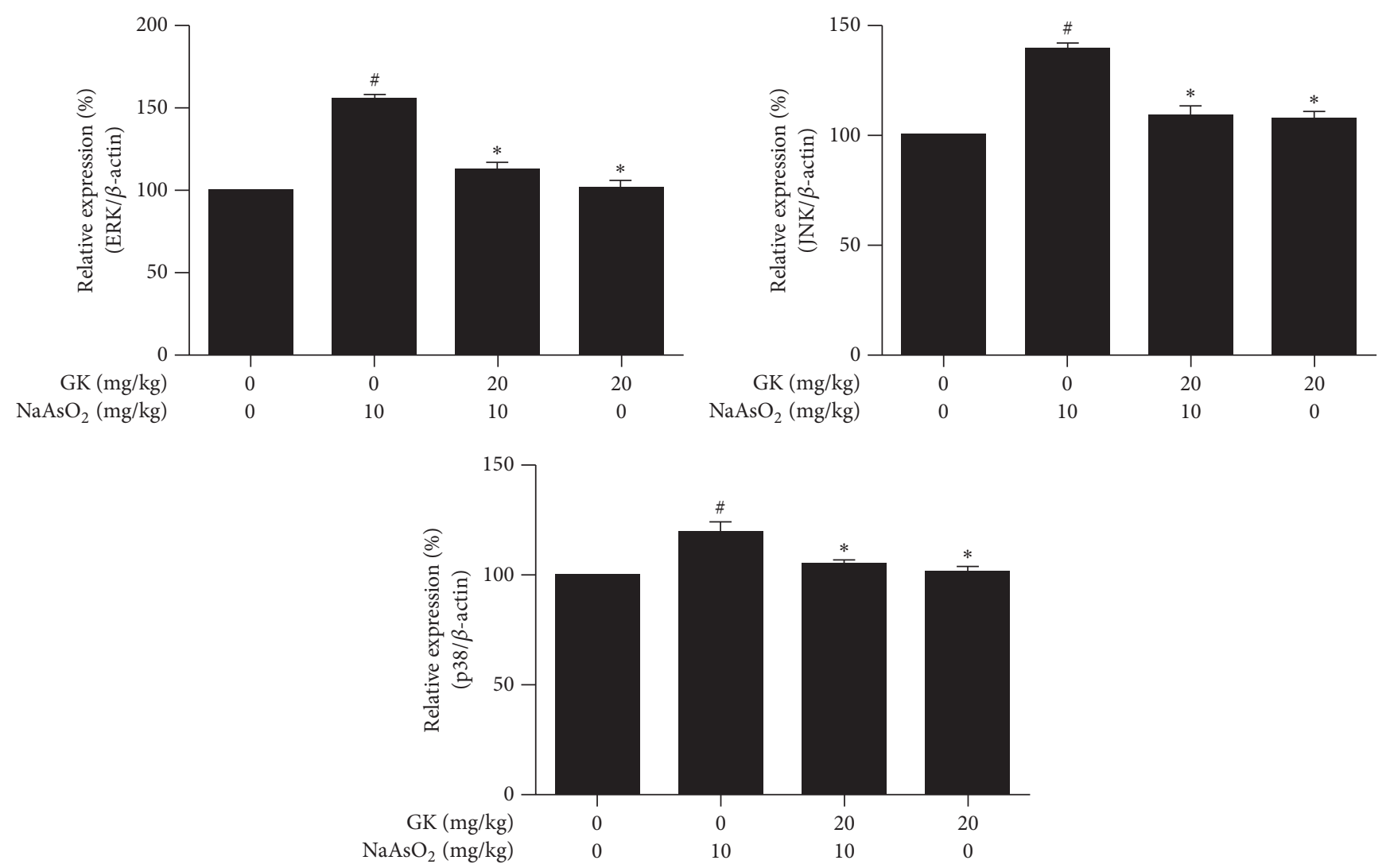

FIGURE 6: GK attenuated mRNA expression level of MAPK (ERK, JNK, and p38) in the liver tissue. In $\mathrm{NaAsO}_{2}(10 \mathrm{mg} / \mathrm{kg})$ treated mice liver tissue, mRNA expression levels of ERK, JNK, and p38 were significantly upregulated while cotreatment with GK (20 mg/kg) markedly downregulated expression level. ${ }^{*} p<0.05$ when compared with the control and ${ }^{*} p<0.05$ when compared with $\mathrm{NaAsO}_{2}$ treated. Data are expressed as mean \pm SEM.

pathways are all influenced by arsenic [37]. Upregulation of ROS generation by inorganic arsenic compounds is known to damage cell membranes via lipid peroxidation, which is a fundamental cellular deteriorating vector in liver cells [38]. Several studies have indicated that ROS production and elevated lipid peroxidation are combined effects of oxidative stress on the development of arsenic hepatotoxicity $[39,40]$. In this study, $\mathrm{NaAsO}_{2}$ exposure to HepG2 cells resulted in a significant increase in both ROS and LDH level, which confirmed the oxidative damage. Cotreatment of GK markedly attenuated the elevation of both ROS and lactate dehydrogenase release in HepG2 cells. This might be due to the antioxidant properties of GK that defended against radical attacks and maintained the normal physiology of the cell membrane.

Because of its metabolic roles and association with the gastrointestinal tract, the liver is vulnerable to toxicity induced by xenobiotics [41]. Histopathology and serum biochemistry serve as an initial indicator of physiological dysfunction and the incidence of liver intoxication $[42,43]$. To observe $\mathrm{NaAsO}_{2}$-induced liver alterations, we performed histopathology on liver tissues. We detected degeneration of the nucleus, enlargement of the portal vein, and blurring of the cytoplasm in $\mathrm{NaAsO}_{2}$-treated liver tissue when compared with untreated control. Improved hepatocyte architecture was found in GK cotreated mice as related to $\mathrm{NaAsO}_{2}$ alone which has been revealed by an earlier study [44]. We, therefore, tested the level of biochemical parameters (ALT and AST) to further support our results. Serum ALT and AST levels were both found to be significantly increased only in the $\mathrm{NaAsO}_{2}$ exposure group as compared with the control group. However, coadministration of GK along with $\mathrm{NaAsO}_{2}$ remarkably altered the serum biochemical parameters to near normal level. These data suggest that GK has the potential to reduce $\mathrm{NaAsO}_{2}$-induced hepatotoxicity. Moreover, cotreatment with GK significantly increased the body weight than $\mathrm{NaAsO}_{2}$ alone.

MAPK include a family of serine/threonine phosphorylating proteins that mediate a variety of signal transduction pathways and are involved in gene expression related to regulation of inflammation, cell proliferation, and cell death [45]. ERK, JNK, and p38 were activated in response to ROS production and mitochondrial dysfunction, which are usually related to cell apoptosis [46]. To consider the basic mechanisms of apoptosis in $\mathrm{NaAsO}_{2}$ intoxicated liver and the protective role of GK in this hepatic pathophysiology, we examined the expression level of ERK, JNK, and p38 by qPCR and immunoblot analyses. We found a marked increase in both mRNA and phosphorylated protein expression of MAPK by $\mathrm{NaAsO}_{2}$ intoxication. Our results demonstrated 


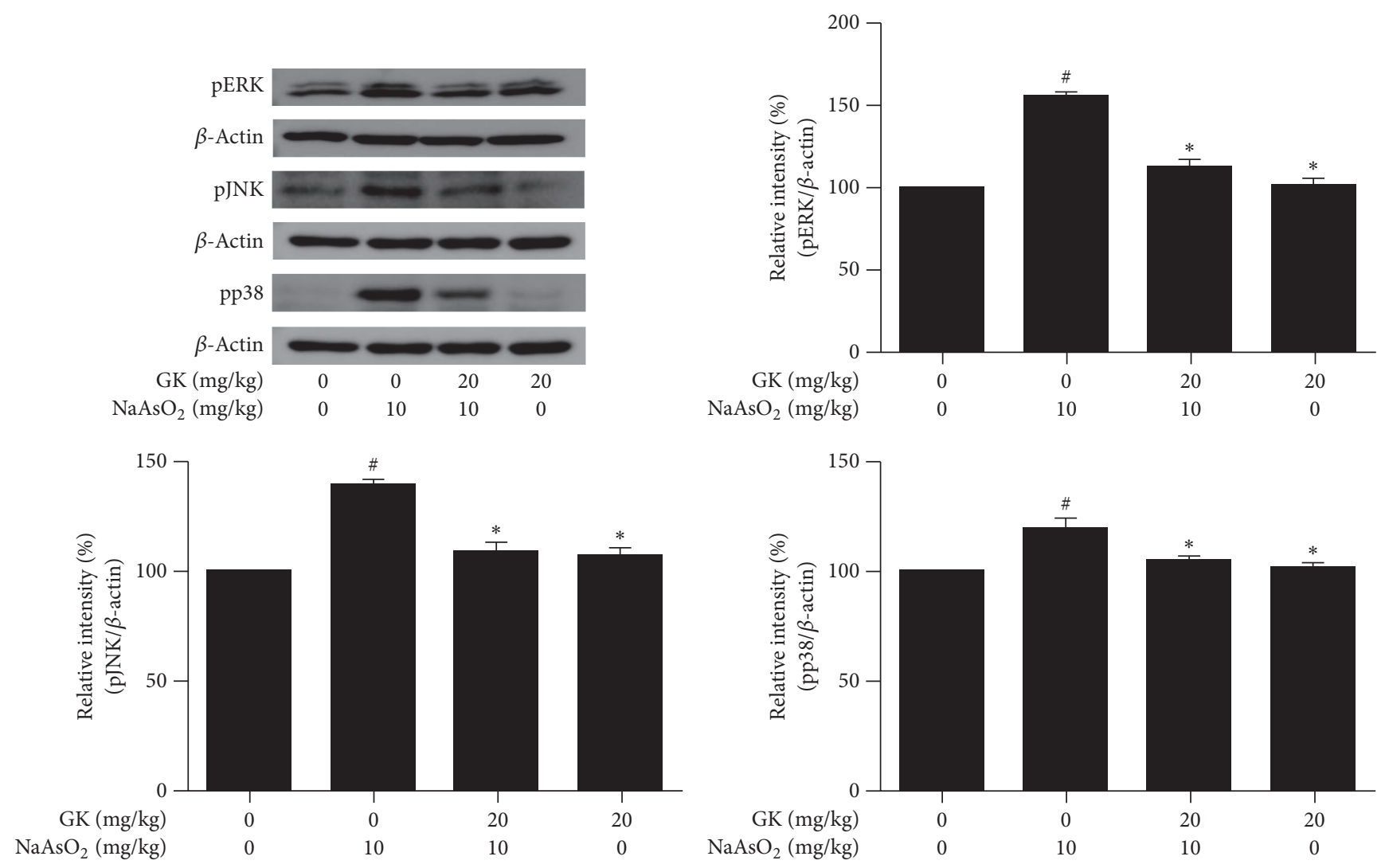

FIGURE 7: Immunoblotting analysis of MAPK (pERK, pJNK, and pp38) in liver tissue. Relative band intensity was measured as compared with $\beta$-actin. In $\mathrm{NaAsO}_{2}(10 \mathrm{mg} / \mathrm{kg})$ treated mice, phosphorylation of ERK, JNK, and p38 was significantly upregulated while cotreatment with GK $(20 \mathrm{mg} / \mathrm{kg})$ markedly downregulated the expression level. ${ }^{*} p<0.05$ when compared with the control and ${ }^{*} p<0.05$ when compared with $\mathrm{NaAsO}_{2}$ treated. Data are expressed as mean \pm SEM.

the ability of $\mathrm{NaAsO}_{2}$ to induce the phosphorylation of $\mathrm{ERK} 1 / 2$, JNK, and $\mathrm{p} 38$ in liver tissues which are in agreement with a previous study [13] and the enhancement of phosphorylation of MAPK plays an important role in the signaling pathway of apoptosis. We found that cotreatment with GK significantly downregulated the activation of ERK, JNK, and p38 indicating that this MAPK pathway was involved with the protection of liver damage by GK.

Oxidative stress-induced apoptosis is primarily executed by upregulation of proapoptotic (Bax) and downregulation of antiapoptotic (Bcl-2 family) proteins and release of cytochrome $c$, which initiates caspase-dependent cell death. The $\mathrm{Bax} / \mathrm{Bcl}-2$ ratio is correlated with cell apoptosis [47]. Bcl2 functions to inhibit cell death, while Bax, which forms heterodimers with Bcl-2, acts to accelerate cell death [48]. Our results showed that Bax expression significantly increased while $\mathrm{Bcl}-2$ expression significantly decreased in $\mathrm{NaAsO}_{2}$ induced hepatotoxicity. In contrast, cotreatment with GK inhibited the proapoptotic Bax and increased the antiapoptotic Bcl-2 expression, indicating diminished hepatic damage. Arsenic-induced mitochondrial damage by increased oxidative stress and reciprocal regulation of $\mathrm{Bax} / \mathrm{Bcl}-2$ association with activation of caspase-3 ultimately led to apoptotic cell death [49]. During apoptosis, proapoptotic Bcl2 protein relocates to the surface of mitochondria and thereby permeabilization of the mitochondrial membrane with release of cytochrome $c$. Cytochrome $c$ promotes the ATP-dependent formation of apoptosome by aggregation of caspase- 9 activation. Caspase- 9 then prompts the caspase cascade by stimulating caspase-3 leading to apoptosis [50]. We found that $\mathrm{NaAsO}_{2}$ exposure led to cleaved caspase- 3 activation suggesting induction of apoptosis. However, the transcription level of apoptotic protein activated caspase3 was significantly restored near normal condition by GK cotreatment. Therefore, our results revealed that GK considerably regulates $\mathrm{NaAsO}_{2}$-induced mitochondrial-dependent oxidative damage in the liver. A further experiment is needed to identify the active compounds in GK methanolic extracts involved in hepatoprotective activities.

\section{Conclusions}

Taken together, our results demonstrate that GK extract attenuated the $\mathrm{NaAsO}_{2}$-induced hepatotoxicity both in vivo and in vitro. GK appears to exert its hepatoprotective role by attenuating cytotoxicity and free radical generation in HepG2 cells. Moreover, GK restores the hepatic physiology and reduction in the mitochondrial-dependent hepatotoxicity. Thus, GK, a natural phytomedicine, may be a promising indigenous therapeutic agent for treatment of hepatic disorders by targeting oxidative stress. 

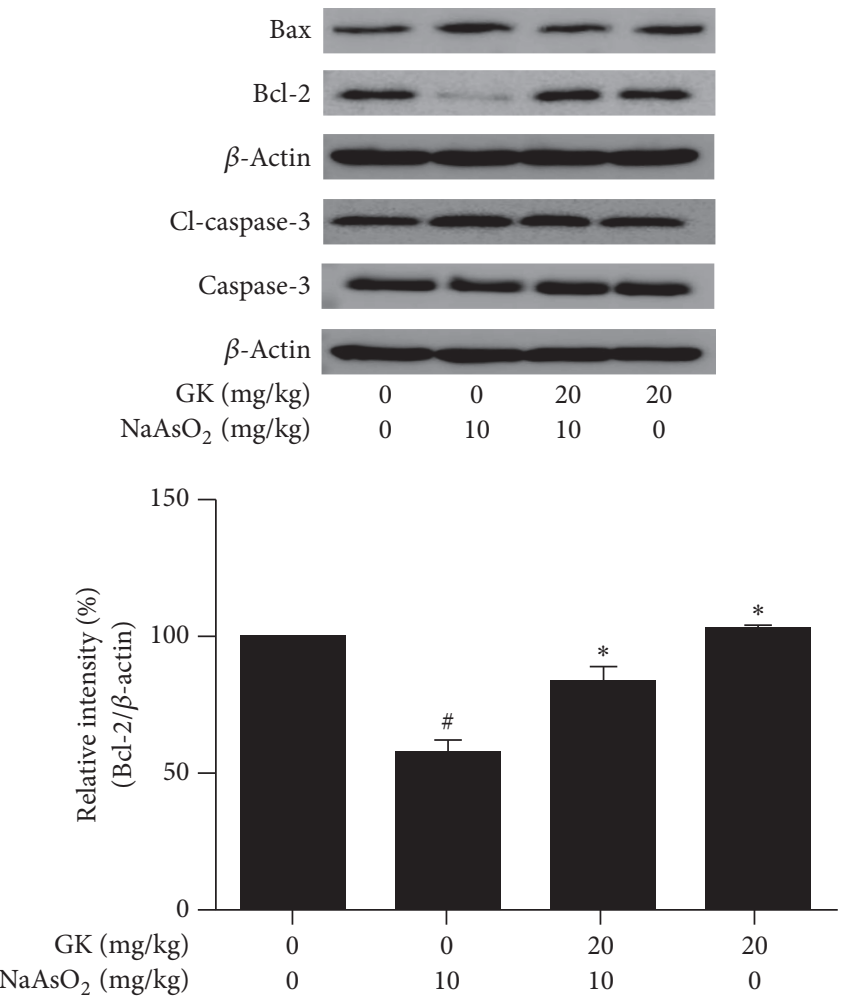
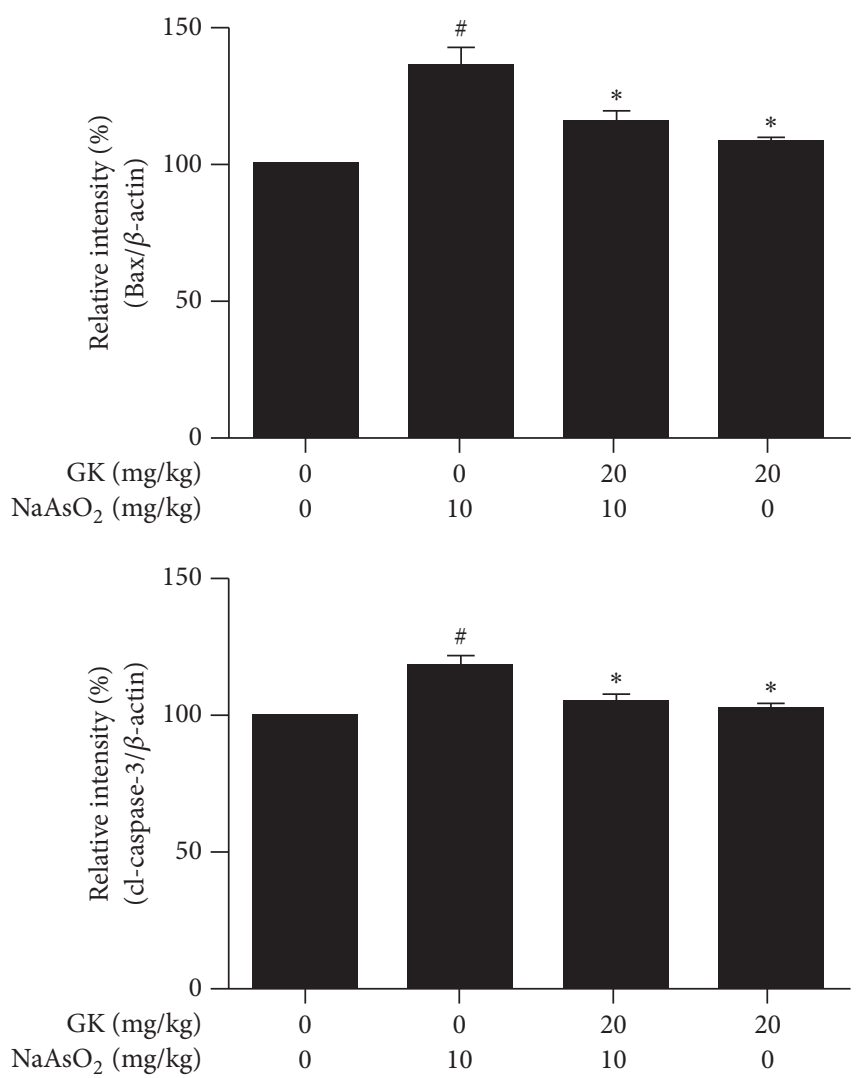

FIGURE 8: Immunoblot analysis of Bax, Bcl-2, and cleaved caspase-3 in liver tissue. Relative band intensity was measured as compared with $\beta$-actin. In $\mathrm{NaAsO}_{2}(10 \mathrm{mg} / \mathrm{kg})$ treated mice, protein expression level of Bax and cleaved caspase-3 was significantly upregulated, and Bcl2 was downregulated while cotreatment with GK $(20 \mathrm{mg} / \mathrm{kg})$ markedly downregulated expression level of Bax and cleaved caspase-3 and upregulated Bcl-2 expression. ${ }^{\#} p<0.05$ when compared with the control and ${ }^{*} p<0.05$ when compared with NaAsO2 treated. Data are expressed as mean \pm SEM.

\section{Abbreviations}

GK: Geranium koreanum

MTT: 3-(4,5-Dimethylthiazol-2-yl)-2,5diphenyltetrazolium bromide

DMEM: Dulbecco's modified Eagle's medium

FBS: $\quad$ Fetal bovine serum

ROS: $\quad$ Reactive oxygen species

LDH: $\quad$ Lactate dehydrogenase

DMSO: Dimethyl sulfoxide

O.D: $\quad$ Optical density

qPCR: Quantitative real-time polymerase chain reaction

MAPK: $\quad$ Mitogen-activated protein kinases

ERK: $\quad$ Extracellular signal-regulated kinases

JNK: c-Jun N-terminal kinase

ALT: $\quad$ Alanine aminotransferase

AST: $\quad$ Aspartate aminotransferase

NBF: $\quad$ Neutral buffered formalin

SDS-PAGE: Sodium dodecyl sulfate-polyacrylamide gel electrophoresis

TBST: $\quad$ Tris-buffered saline

PBST: $\quad$ Phosphate-buffered saline

ECL: $\quad$ Enhanced chemiluminescence
T-PER: Tissue protein extraction reagent

PMSF: Phenylmethylsulfonyl fluoride

Na3VO4: Sodium orthovanadate.

\section{Conflicts of Interest}

There are no conflicts of interest to declare.

\section{Acknowledgments}

This research was supported by Basic Science Research Program through the National Research Foundation of Korea (NRF) funded by the Ministry of Education (2017R1D1A1B03035765).

\section{References}

[1] P. Srivastava, R. S. Yadav, L. P. Chandravanshi et al., "Unraveling the mechanism of neuroprotection of curcumin in arsenic induced cholinergic dysfunctions in rats," Toxicology and Applied Pharmacology, vol. 279, no. 3, pp. 428-440, 2014.

[2] B. K. Mandal and K. T. Suzuki, "Arsenic round the world: a review," Talanta, vol. 58, no. 1, pp. 201-235, 2002. 
[3] M. Messarah, F. Klibet, A. Boumendjel et al., "Hepatoprotective role and antioxidant capacity of selenium on arsenic-induced liver injury in rats," Experimental and Toxicologic Pathology, vol. 64, no. 3, pp. 167-174, 2012.

[4] X. Cui, Y. Kobayashi, M. Akashi, and R. Okayasu, "Metabolism and the paradoxical effects of arsenic: carcinogenesis and anticancer," Current Medicinal Chemistry, vol. 15, no. 22, pp. 2293-2304, 2008.

[5] M. F. Hughes, B. D. Beck, Y. Chen, A. S. Lewis, and D. J. Thomas, "Arsenic exposure and toxicology: a historical perspective," Toxicological Sciences, vol. 123, no. 2, pp. 305-332, 2011.

[6] R. Ruiz-Ramos, L. Lopez-Carrillo, A. D. Rios-Perez, A. de Vizcaya-Ruíz, and M. E. Cebrian, "Sodium arsenite induces ROS generation, DNA oxidative damage, HO-1 and c-Myc proteins, NF- $\kappa \mathrm{B}$ activation and cell proliferation in human breast cancer MCF-7 cells," Mutation Research/Genetic Toxicology and Environmental Mutagenesis, vol. 674, no. 1-2, pp. 109-115, 2009.

[7] T. K. Hei and M. Filipic, "Role of oxidative damage in the genotoxicity of arsenic," Free Radical Biology \& Medicine, vol. 37, no. 5, pp. 574-581, 2004.

[8] Z. Durackova, "Some current insights into oxidative stress," Physiological Research, vol. 59, no. 4, pp. 459-469, 2010.

[9] K. T. Kitchin and R. Conolly, "Arsenic-induced carcinogenesissoxidative stress as a possible mode of action and future research needs for more biologically based risk assessment," Chemical Research in Toxicology, vol. 23, no. 2, pp. 327-335, 2010.

[10] P. Watcharasit, A. Thiantanawat, and J. Satayavivad, "GSK3 promotes arsenite-induced apoptosis via facilitation of mitochondria disruption," Journal of Applied Toxicology, vol. 28, no. 4, pp. 466-474, 2008.

[11] P. Muriel and K. R. Gordillo, "Role of oxidative stress in liver health and disease," Oxidative Medicine and Cellular Longevity, vol. 2016, Article ID 9037051, 2 pages, 2016.

[12] S. J. S. Flora, A. Mehta, and R. Gupta, "Prevention of arsenicinduced hepatic apoptosis by concomitant administration of garlic extracts in mice," Chemico-Biological Interactions, vol. 177, no. 3, pp. 227-233, 2009.

[13] T. Suzuki and I. Tsukamoto, "Arsenite induces apoptosis in hepatocytes through an enhancement of the activation of Jun $\mathrm{N}$-terminal kinase and p38 mitogen-activated protein kinase caused by partial hepatectomy," Toxicology Letters, vol. 165, no. 3, pp. 257-264, 2006.

[14] Y. Liu, K. Z. Guyton, M. Gorospe, Q. Xu, J. C. Lee, and N. J. Holbrook, "Differential activation of ERK, JNK/SAPK and P38/CSBP/RK map kinase family members during the cellular response to arsenite," Free Radical Biology and Medicine, vol. 21, no. 6, pp. 771-781, 1996.

[15] T. Wada and J. M. Penninger, "Mitogen-activated protein kinases in apoptosis regulation," Oncogene, vol. 23, no. 16, pp. 2838-2849, 2004.

[16] S. Cagnol and J. C. Chambard, "ERK and cell death: mechanisms of ERK-induced cell death-apoptosis, autophagy and senescence," FEBS Journal, vol. 277, no. 1, pp. 2-21, 2010.

[17] A. Gross, J. M. McDonnell, and S. J. Korsmeyer, "BCL-2 family members and the mitochondria in apoptosis," Genes and Development, vol. 13, no. 15, pp. 1899-1911, 1999.

[18] I. Kitazumi and M. Tsukahara, "Regulation of DNA fragmentation: the role of caspases and phosphorylation," FEBS Journal, vol. 278, no. 3, pp. 427-441, 2011.

[19] S. Bashir, Y. Sharma, M. Irshad, S. D. Gupta, and T. D. Dogra, "Arsenic-induced cell death in liver and brain of experimental rats," Basic and Clinical Pharmacology and Toxicology, vol. 98, no. 1, pp. 38-43, 2006.

[20] C. Chen, X. Jiang, W. Zhao, and Z. Zhang, "Dual role of resveratrol in modulation of genotoxicity induced by sodium arsenite via oxidative stress and apoptosis," Food and Chemical Toxicology, vol. 59, pp. 8-17, 2013.

[21] M. Ming, L. Guanhua, Y. Zhanhai, C. Guang, and Z. Xuan, "Effect of the Lycium barbarum polysaccharides administration on blood lipid metabolism and oxidative stress of mice fed highfat diet in vivo," Food Chemistry, vol. 113, no. 4, pp. 872-877, 2009.

[22] S. Saeidnia and M. Abdollahi, "Antioxidants: friends or foe in prevention or treatment of cancer: the debate of the century," Toxicology and Applied Pharmacology, vol. 271, no. 1, pp. 49-63, 2013.

[23] M. Negrette-Guzmán, S. Huerta-Yepez, O. N. Medina-Campos et al., "Sulforaphane attenuates gentamicin-induced nephrotoxicity: role of mitochondrial protection," Evidence-Based Complementary and Alternative Medicine, vol. 2013, Article ID 135314, 17 pages, 2013.

[24] J.-Y. Oh, K.-J. Lee, B. Wei et al., "Antibacterial activities of bark extracts from Fraxinus rhynchophylla Hance and Geranium koreanum Kom. Against clinical strains of Clostridium perfringens in chickens," Korean Journal of Veterinary Research, vol. 55, no. 2, pp. 117-123, 2015.

[25] L. Jing, H. Ma, P. Fan, R. Gao, and Z. Jia, "Antioxidant potential, total phenolic and total flavonoid contents of Rhododendron anthopogonoides and its protective effect on hypoxia-induced injury in PC12 cells," BMC Complementary and Alternative Medicine, vol. 15, article 287, 2015.

[26] J. C. Stockert, A. Blázquez-Castro, M. Cañete, R. W. Horobin, and Á. Villanueva, "MTT assay for cell viability: intracellular localization of the formazan product is in lipid droplets," Acta Histochemica, vol. 114, no. 8, pp. 785-796, 2012.

[27] T. K. Dua, S. Dewanjee, M. Gangopadhyay, R. Khanra, M. Zia-Ul-Haq, and V. De Feo, "Ameliorative effect of water spinach, Ipomea aquatica (Convolvulaceae), against experimentally induced arsenic toxicity," Journal of Translational Medicine, vol. 13, no. 1, article 81, 2015.

[28] M. K. Tuck, D. W. Chan, D. Chia et al., "Standard operating procedures for serum and plasma collection: early detection research network consensus statement standard operating procedure integration working group," Journal of Proteome Research, vol. 8, no. 1, pp. 113-117, 2009.

[29] M. R. Akanda, M. J. Kim, I. S. Kim et al., "Neuroprotective effects of sigesbeckia pubescens extract on glutamateinduced oxidative stress in HT22 cells via downregulation of MAPK/caspase-3 pathways," Cellular and Molecular Neurobiology, pp. 1-9, 2017.

[30] H. Chavan, M. Oruganti, and P. Krishnamurthy, "The ATPbinding cassette transporter ABCB6 is induced by arsenic and protects against arsenic cytotoxicity," Toxicological Sciences, vol. 120, no. 2, pp. 519-528, 2011.

[31] J. Brinkel, M. H. Khan, and A. Kraemer, "A systematic review of arsenic exposure and its social and mental health effects with special reference to Bangladesh," International Journal of Environmental Research and Public Health, vol. 6, no. 5, pp. 1609-1619, 2009.

[32] D. Lin, M. Xiao, J. Zhao et al., "An overview of plant phenolic compounds and their importance in human nutrition and management of type 2 diabetes," Molecules, vol. 21, no. 10, article 1374, 2016. 
[33] J. Mierziak, K. Kostyn, and A. Kulma, "Flavonoids as important molecules of plant interactions with the environment," Molecules, vol. 19, no. 10, pp. 16240-16265, 2014.

[34] J. P. Dzoyem and J. N. Eloff, "Anti-inflammatory, anticholinesterase and antioxidant activity of leaf extracts of twelve plants used traditionally to alleviate pain and inflammation in South Africa," Journal of Ethnopharmacology, vol. 160, no. 3, pp. 194-201, 2015.

[35] A. Ghosh, A. K. Mandal, S. Sarkar, and N. Das, "Hepatoprotective and neuroprotective activity of liposomal quercetin in combating chronic arsenic induced oxidative damage in liver and brain of rats," Drug Delivery, vol. 18, no. 6, pp. 451-459, 2011.

[36] A. Adewale and A. E. Olorunju, "Modulatory of effect of fresh amaranthus caudatus and amaranthus hybridus aqueous leaf extracts on detoxify enzymes and micronuclei formation after exposure to sodium arsenite," Pharmacognosy Research, vol. 5, no. 4, pp. 300-305, 2013.

[37] M. F. Hughes, "Arsenic toxicity and potential mechanisms of action," Toxicology Letters, vol. 133, no. 1, pp. 1-16, 2002.

[38] K. Jomova and M. Valko, "Advances in metal-induced oxidative stress and human disease," Toxicology, vol. 283, no. 2-3, pp. 6587, 2011.

[39] W. Zhang, J. Xue, M. Ge, M. Yu, L. Liu, and Z. Zhang, "Resveratrol attenuates hepatotoxicity of rats exposed to arsenic trioxide," Food and Chemical Toxicology, vol. 51, no. 1, pp. 87-92, 2013.

[40] T. Yamamoto, R. Kikkawa, H. Yamada, and I. Horii, "Identification of oxidative stress-related proteins for predictive screening of hepatotoxicity using a proteomic approach," The Journal of Toxicological Sciences, vol. 30, no. 3, pp. 213-227, 2005.

[41] J. Liu and M. P. Waalkes, "Liver is a target of arsenic carcinogenesis," Toxicological Sciences, vol. 105, no. 1, pp. 24-32, 2008.

[42] A. S. Noman, S. Dilruba, N. C. Mohanto et al., "Arsenic-induced histological alterations in various organs of mice," Journal of Cytology \& Histology, vol. 6, no. 3, 2015.

[43] S. Gowda, P. B. Desai, V. V. Hull, A. A. Math, S. N. Vernekar, and S. S. Kulkarni, "A review on laboratory liver function tests," Pan African Medical Journal, vol. 3 article 17, 2009.

[44] T. K. Dua, S. Dewanjee, and R. Khanra, "Prophylactic role of Enhydra fluctuans against arsenic-induced hepatotoxicity via anti-apoptotic and antioxidant mechanisms," Redox Report, vol. 21, no. 4, pp. 147-154, 2016.

[45] Z. Xia, M. Dickens, J. Raingeaud, R. J. Davis, and M. E. Greenberg, "Opposing effects of ERK and JNK-p38 MAP kinases on apoptosis," Science, vol. 270, no. 5240, pp. 1326-1331, 1995.

[46] A. Matsuzawa and H. Ichijo, "Redox control of cell fate by MAP kinase: physiological roles of ASK1-MAP kinase pathway in stress signaling," Biochimica et Biophysica Acta-General Subjects, vol. 1780, no. 11, pp. 1325-1336, 2008.

[47] G. C. Shore and M. Nguyen, "Bcl-2 proteins and apoptosis: choose your partner," Cell, vol. 135, no. 6, pp. 1004-1006, 2008.

[48] Z. N. Oltvai, C. L. Milliman, and S. J. Korsmeyer, "Bcl-2 heterodimerizes in vivo with a conserved homolog, Bax, that accelerates programed cell death," Cell, vol. 74, no. 4, pp. 609619, 1993.

[49] J. Das, J. Ghosh, P. Manna, and P. C. Sil, "Protective role of taurine against arsenic-induced mitochondria-dependent hepatic apoptosis via the inhibition of PKCdelta-JNK pathway," PloS One, vol. 5, no. 9, Article ID e12602, 2010.
[50] C.-C. Wu, S. Lee, S. Malladi et al., "The Apaf-1 apoptosome induces formation of caspase- 9 homo- and heterodimers with distinct activities," Nature Communications, vol. 7, Article ID $13565,2016$. 


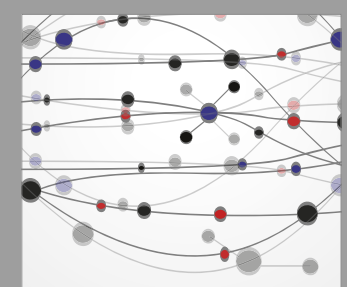

The Scientific World Journal
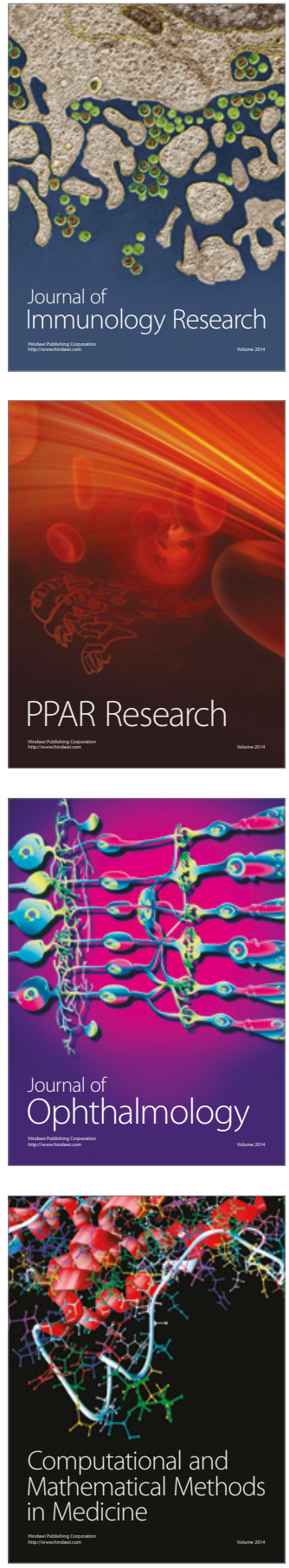

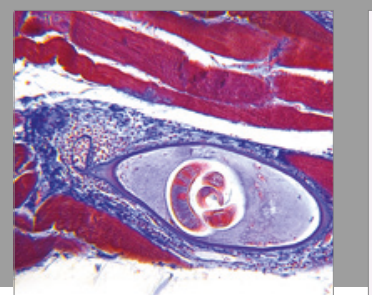

Gastroenterology Research and Practice
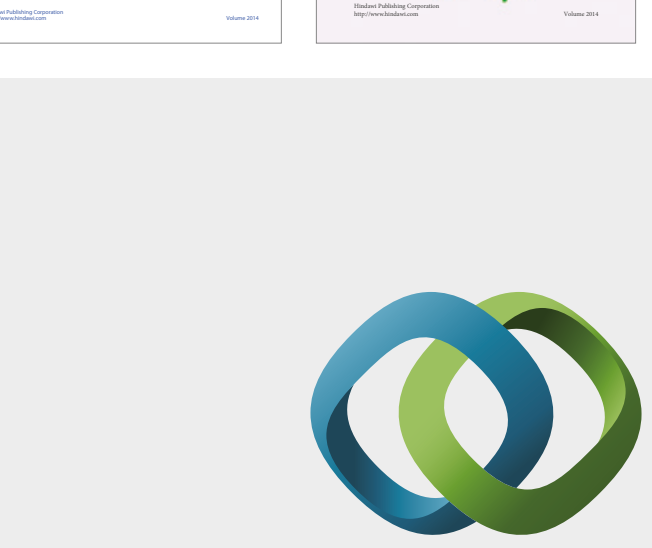

\section{Hindawi}

Submit your manuscripts at

https://www.hindawi.com
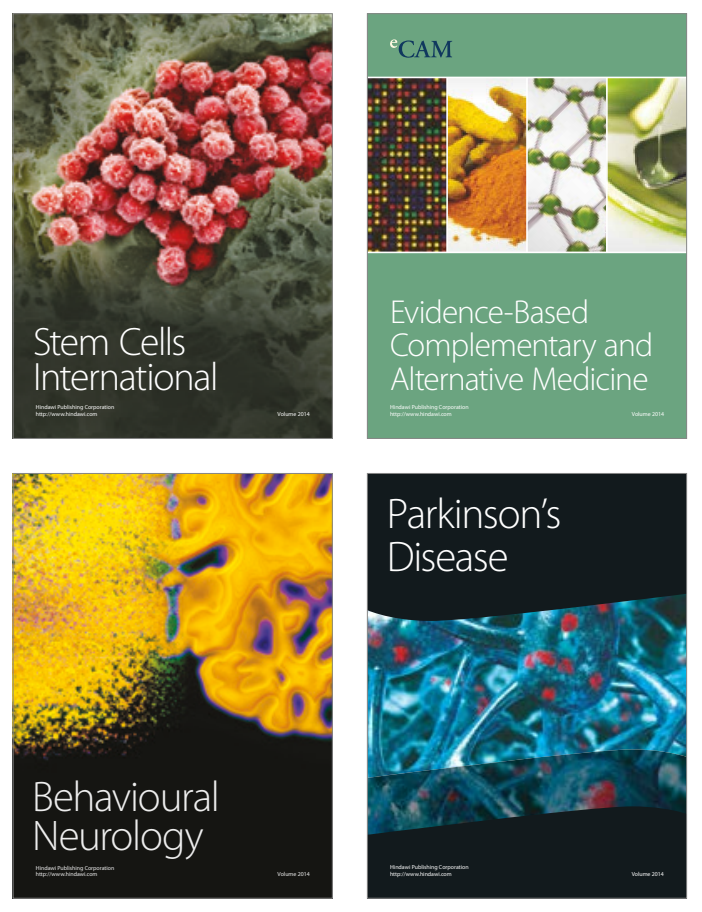
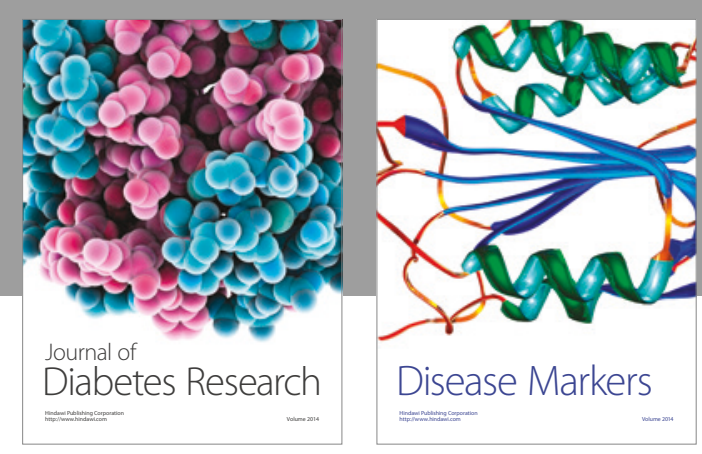

Disease Markers
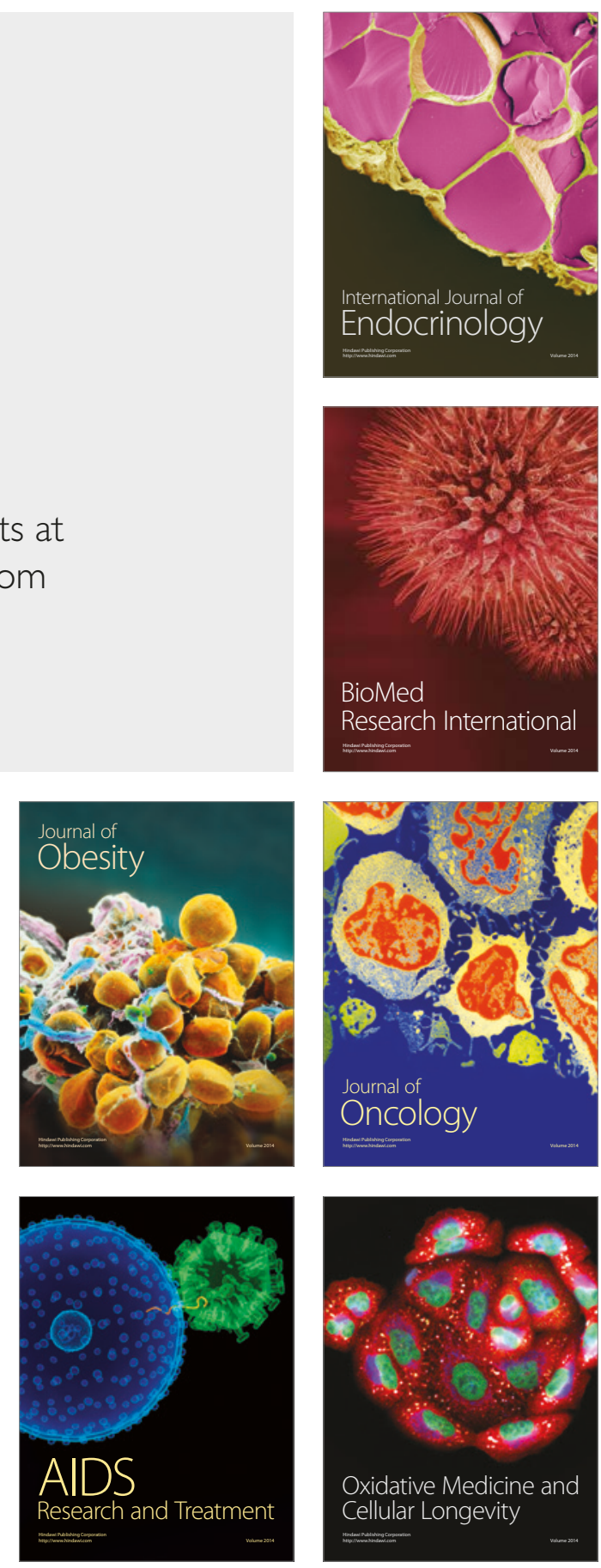